\title{
O ritual do toré como organizador prévio para o conceito de círculo
}

\section{The toré ritual as a previous organizer to the concept of circle}

\author{
José Roberto da Silva ${ }^{1}$ \\ Evilásio Clecio de Souza ${ }^{2}$ \\ Maria Aparecida da Silva Rufino ${ }^{3}$
}

\begin{abstract}
Resumo
As lutas dos indígenas brasileiros devem-se, em parte, à preservação das suas terras contra fazendeiros e políticos. No caso dos Pankará, a adversidade levou-os ao reconhecimento étnico, à manutenção do território e ao direito de vivenciarem as suas práticas culturais na escola. Este estudo recorre ao ritual sagrado do toré, visando produzir um material educativo como organizador prévio para o(a) educador(a) indígena negociar significados interculturais entre a sua própria cultura e o saber escolar institucionalizado. O objetivo do material produzido é aludir metaforicamente às idealizações geométricas de círculo e dos seus elementos com o saber não indígena, e com isso despertar cultural e cientificamente o interesse de crianças pankará pelo saber matemático.
\end{abstract}

Palavras-chave: Ritual do toré; organizador prévio; conceito de círculo; educador indígena pankará.

\begin{abstract}
Most struggles of indigenous peoples in Brazil are due in part to preserving their territory from farmers and politicians. The Pankará people, however, has overcome adversities to get its ethnicity recognized, maintain its territory, and live its culture at school. This study uses the sacred ritual of the toré in order to produce a pedagogical material as a previous organizer for Pankará educators to negotiate their cultural meanings between their own culture and the institutionalized knowledge. The pedagogical material approaches the geometrical idealizations of circle and its elements metaphorically as a non-indigenous knowledge to interest the Indigenous people culturally and scientifically.
\end{abstract}

Keywords: Toré ritual; previous organizer; concept of circle; Pankará educators.

\section{Introdução}

O povo pankará ${ }^{4}$ habita o semiárido do sertão pernambucano, precisamente a Serra do Arapuá, localizada no município de Carnaubeira da Penha. A sua população é de

${ }^{1}$ Doctor en Enseñanza de la ciências pela universidad de Burgos, España. Professor da Universidade de Pernambuco-Camus Mata Norte, Brasil.jrobertosilva@bol.com.br

2 Especialista em Ensino de Matemática pela Faculdade de Formação de Professores de Serra TalhadaFAFOPST, Pernambuco, Brasil. Educador indígena pankará. evilasiomandaru@gmail.com

${ }^{3}$ Doctora en Enseñanza de la ciências pela universidad de Burgos, España. Professora da Universidade de Pernambuco-Camus Mata Norte, Brasil. aparecidarufino@ hotmail.com

4 Adotou-se aqui a grafia dos etnônimos brasílicos estabelecida pela "Convenção para a grafia dos nomes tribais", na $1^{\text {a }}$ Reunião Brasileira de Antropologia, realizada no Rio de Janeiro, em novembro de 1953; segundo a qual, os substantivos e adjetivos são invariáveis e grafam-se, no caso dos primeiros, com inicial maiúscula. 
DOI: https://doi.org/ 10.20396/zet.v26il.8650471

aproximadamente 5.000 mil indígenas, segundo informações obtidas do seu conselho de anciãos; esse número subdivide-se em seis núcleos, com um total de 58 aldeias. A sua preservação deve-se ao seu engajamento, às mobilizações sociopolíticas e resistências desde o século XIX.

A história dos Pankará - como as dos demais indígenas brasileiros - tem sido marcada por tentativas de anulação cultural por parte dos não indígenas. Como forma natural de subsistência, diante de conflitos e desafios e impulsionados pela força de coesão, a população teve a sua cidadania reconhecida e avançou em outras conquistas. $\mathrm{O}$ reconhecimento oficial da etnia só ocorreu por volta da década de 40 do século passado, porém a demarcação das suas terras - conquista atribuída por eles aos enormes esforços do pai Tupã, da mãe Tamain e dos encantados - só se concretizou em meados de 2003.

As mobilizações sociopolíticas pela subsistência apresentam as mesmas características dos demais povos indígenas no Brasil. O interesse deste estudo, no entanto, não está nas dificuldades de conquistas por direitos - como o resgate das suas terras no estado de Pernambuco -, mas por condições para ampliar a qualidade das práticas educativas indígenas. Assim, as mobilizações passam a ser pela busca de garantias de uma escola em que a educação seja específica, diferenciada e de qualidade, respeitando as suas manifestações culturais e as suas organizações sociopolíticas.

A resistência dos povos indígenas, como ressaltado, ancora-se sempre na união de um povo intencionado em manter viva a força necessária para prosseguir na luta pelos seus objetivos. Não há como um povo proliferar sem encontrar formas viáveis para estabelecer-se e difundir a sua cultura por gerações que, nesse caso, consiste desde a confecção de artesanatos, agricultura, cultivo de plantas medicinais a rituais sagrados, como a dança do toré, elemento cultural que embasa este estudo.

O processo de criação e difusão cultural sistematizada passa pela escolarização, que cabe, entre outros órgãos componentes, à Organização Interna de Educação Escolar Indígena Pankará (OIEEIP). A OIEEIP tem por finalidade fortalecer a identidade étnica dos educandos como patrimônio natural, cultural e sócio-histórico, deixado pelos seus antepassados. É o que diz Ribeiro (2002) sobre a cultura precisar ser repassada aos descendentes para não se perder toda uma história, os conhecimentos e os saberes específicos, na medida em que representam o maior patrimônio da humanidade.

A educação no território pankará é uma das grandes conquistas e foi comemorada com o mesmo entusiasmo quando do reconhecimento oficial da etnia, na década de 40 do século passado, guardadas as devidas proporções. Antes, porém, não se podia desenvolver qualquer ação que caracterizasse uma identificação própria do povo.

As lideranças pankará afirmam que a sua cultura era desrespeitada pela sociedade. Qualquer atividade cultural devia ser vivenciada às escondidas, fora do horário escolar, para não serem surpreendidos praticando costumes e tradições próprias. Mas as atenções pedagógicas deste estudo voltam-se para duas situações seguintes, colocadas por Barbalho 
DOI: https://doi.org/ 10.20396/zet.v26il.8650471

(2012, p. 24) acerca do cenário discursivo sobre a organização escolar pleiteada pelos indígenas: "i) a relação entre teoria e prática educacional, revelando a natureza complexa da base epistemológica das proposições interculturais; ii) e os variados percursos da formação de professores/as e estudantes na luta por processos 'inclusivos' mais democráticos e autônomos".

Lamentavelmente, ainda há escolas indígenas que vivenciam algum tipo de repressão cultural; no entanto, é preciso fazer a sociedade brasileira compreender essas atrocidades para ajudar a impedir que as agressões continuem impactando negativamente o desenvolvimento dos povos indígenas. Após a demarcação das terras, em 2003, as suas escolas estadualizaramse e reorganizaram-se, passando a ter características de instituições indígenas.

A educação pankará apoia-se em diretrizes nacionais e estaduais como aporte para a planificação do Projeto Político Pedagógico do povo Pankará (Pernambuco, 2012). Nesse documento, produzido coletivamente, há referência ao uso de materiais e procedimentos de natureza didático-epistemológico-metodológica produzidos pela própria comunidade, em cumprimento às exigências do Programa de Educação Indígena (PEI) brasileiro.

$\mathrm{O}$ (a) educador(a) pankará precisa cumprir o perfil de guerreiro(a) indígena, que passa pela prática ativa do ritual, do respeito à diversidade cultural, do conhecimento da própria história e do processo de mobilização sociopolítica e ocupação do território. Veem-se esses(as) professores(as) como janelas que servem de passagem para lados distintos e que viabilizam novos conhecimentos e saberes. Por isso, almeja-se identificar questões relevantes do convívio indígena que levem esses(as) professores(as) a reconhecer o papel da troca de significados interculturais na aquisição de conhecimento.

Dentre as atividades vivenciadas na aldeia, optou-se particularmente pelas formas de manifestações indígenas que permitissem estabelecer correspondências entre conteúdos matemáticos institucionalizados e assuntos abordados na educação indígena e vice-versa. Elegeu-se o cerimonial do toré diante da possibilidade metafórica natural de apoio para estabelecerem-se comparações com os conceitos e/ou definições geométricas de círculo, circunferência, centro, raio, corda e diâmetro.

\section{Apresentação dos pressupostos teóricos}

\section{O contexto próprio: contribuições para uma aprendizagem significativa}

O reconhecimento da distinção entre grupos de pessoas a partir de suas línguas, crenças, sistemas de valores, etc. como povos que possuem saberes próprios e modos de desenvolvê-los pode orientar a formulação de abordagens educacionais diversas. Assim, caso essas formulações intencionem melhorar o desempenho das atividades docentes e discentes através das suas manifestações culturais intra e interétnicas, é preciso ampliar este debate. 
Tais distinções são apontadas por muitos pesquisadores. Entretanto, para introduzir a matemática sem mencioná-la diretamente, a citação de D’Ambrósio (1997, p. 18) atende muito bem ao interesse mencionado:

[...] todas as explicações sobre o cosmos, sobre os planetas, sobre a regularidade do dia e da noite, e toda a transformação disso em códigos que sejam sistemas de numeração, sistemas de contagens, etc., são completamente diferentes de um esquimó e de um indígena da Amazônia e diferentes daqueles que moram perto do Mediterrâneo, do egípcio, grego, babilônio, romano, onde durante um período o dia é longo; em outro, o dia é curto.

Em educação matemática, devido às diferenças culturais, não é difícil encontrar estudos que revelem inconveniências nas formas adotadas por pesquisadores para obterem caminhos que minimizem as dificuldades didático-pedagógicas. Uma dessas inconveniências é apontada em Rosa \& Orey (2012), ao destacarem que as investidas nos traços culturais com ênfase nas características superficiais da cultura analisada geram interpretações indevidas acerca do conhecimento dos membros do grupo estudado.

A procura de caminhos para evitar essas interpretações indevidas em estudos com intervenções pedagógicas, podem ser contornadas com a preparação de educadores nativos, mas isso exige certos cuidados importantes. Gerdes (2010), por exemplo, ao se reportar ao desenvolvimento multilinear da matemática destaca que o processo de crescimento das ideias matemáticas depende do tempo e da cultura. Nesse percurso, ele indica três aspectos que devem ser considerados por professores que vivenciam atividades pedagógicas em contexto cultural:

[...] devem estar conscientes de que, geralmente, o desenvolvimento da matemática não é unilinear, e de que a aprendizagem de ideias matemáticas, mesmo num contexto cultural aparentemente homogêneo, não precisa sempre seguir o mesmo caminho.

[...] não está consciente de como diferenças culturais podem gerar desenvolvimentos diferentes na matemática, isto poderá levar a problemas significativos para os(as) aprendizes matemática.

[...] é possível, na base da experiência e do estudo do(a) professor(a), reconhecer ou compreender aspectos matemáticos em contextos culturais diferentes [...] (op. cit., p. $160)$.

Há outra consideração importante a ser apresentada sobre a preparação do educador nativo. É a dimensão da cultura matemática, encontrada nos três níveis de Davies (1973 citado em Bishop, 1999): o informal, o formal e o técnico. Aqui, alude-se ao primeiro deles. Bishop diz que:

1. En el nivel informal todos empleamos las simbolizaciones $\mathrm{y}$ las conceptualizaciones de las Matemáticas de una manera implícita e imprecisa. Las ideas Matemáticas pueden estar en su mayor parte sumergidas en el contexto de la situación y los valores Matemáticos pueden ser anulados por distintas consideraciones emocionales o sociales (1999, p. 115, grifo nosso). 
Ele também menciona que os adultos, ao compartilharem valores e ideias simbólicas da cultura matemática, prestam um serviço de enculturação ${ }^{5}$ informal à família ou à comunidade de que são membros. A atenção dada ao nível informal decorre do fato de pactuar-se com esse pesquisador sobre os currículos centrados no desenvolvimento de técnicas não auxiliarem a aquisição de significados, nem a compreensão, e não oportunizarem o desenvolvimento de uma postura crítica na matemática e fora dela.

As intenções educativas deste estudo não se situam precisamente no nível informal nem no formal, mas numa região de transição entre ambos. Para ilustrar a transição, apresentam-se as duas contextualizações seguintes envolvendo a ideia de círculo, objeto matemático de interesse neste trabalho.

A primeira forma de abordagem tem foco na intuição, "En el comienzo era el círculo. Omnipresente. Suspendido en el cielo en las noches de luna llena; suporte de carros, luego de carruajes, rodeando de piedra las ciudades; decorando vasos que, con su huella, lo dibujarían a su vez sobre la arena. [...]" (Serres, 1991, p. 151). Já na segunda abordagem, a investida é mais formal, procura aprofundar a ideia de círculo e as suas partes constitutivas, reportandose aos Elementos, de Euclides, como segue:

Círculo es una figura plana delimitada por una línea - llamada circunferencia respecto de la cual, a partir de un punto entre los situados en el interior de la figura, todas las rectas que la inciden son - hasta la circunferencia del círculo - iguales entre si. Se llama a este punto centro del círculo (Ibidem).

As duas contextualizações não deixam dúvidas sobre a importância do emprego do círculo, seja no convívio acadêmico, seja fora dele. Como afirma Serres (1991, p. 151), tratase de uma "[f]igura única y reconocible rodeando en el tiempo y el espacio, 'el' círculo sólo se dejaría cobijar por disciplinas y culturas diversas para que éstas iluminen algunas de sus propriedades hasta entonces ocultas o le inventan inéditas aplicaciones".

Esse debate revela que, mesmo diante de uma única idealização como a do círculo, pode haver uma variedade de formas de contextualização capaz de ser adotada com o intuito de melhorar a qualidade do desempenho das tarefas docentes e discentes durante o processo educativo. Assim, desvelar um contexto que acione as relações entre o que o aprendiz já sabe acerca do que se almeja ensinar e o novo objeto de ensino passa a potencializar a aprendizagem no ato educativo.

A expectativa no contexto encontra apoio na suposição ausubeliana de que os seres humanos podem relacionar uma nova informação a um conhecimento relevante, existente na sua estrutura cognitiva, designado de subsunçor, que funciona como ideia-âncora. Por isso, Ausubel preconiza que "[s]e tivesse que reduzir toda a psicologia educacional a um só

\footnotetext{
$5 \mathrm{Na}$ antropologia, a endoculturação, ou enculturação, representa um processo através do qual os indivíduos adquirem e internalizam um sistema de valores, normas, símbolos, crenças e conhecimentos; portanto, significa interiorização, assimilação, apropriação, absorção, aprendizagem. (Assis \& Nepomuceno, 2008).
} 
princípio, dirá o seguinte: o fator isolado mais importante que influencia a aprendizagem é aquilo que o aprendiz já sabe. Averigue isso e ensine-o de acordo" (1978, p. iv).

Segundo Novak (1981), uma nova aprendizagem é significativa se resultar em crescimento e modificação de um subsunçor; e, dependendo da experiência prévia do aprendiz, pode ser relativamente maior e bem desenvolvida, ou limitada, em variedade e quantidade de elementos que contém. A ocorrência da aprendizagem significativa, como lembra Ausubel (2002), não depende apenas da existência de subsunçores mas também da potencialidade significativa do material de aprendizagem e da predisposição do aprendiz.

Ausubel recomenda ainda o uso de organizadores prévios (OPs) para servirem de "ancoradouros provisórios", quando o aprendiz não dispuser de subsunçores ou quando forem inadequados. Os OPs devem preceder o material a ser aprendido em si, porque têm como principal função permitir a relação entre o que o aprendiz sabe e a informação a ser apreendida. Dessa forma, tanto podem fornecer "ideias-âncora" relevantes para a aprendizagem significativa quanto podem estabelecer relações entre ideias, proposições e conceitos existentes na estrutura cognitiva e aqueles contidos no material de aprendizagem.

Quanto ao material de aprendizagem ser ou não familiar ao aprendiz, Ausubel (2002) propõe dois tipos de organizadores: o comparativo e o expositivo. $\mathrm{O}$ expositivo serve para identificar explicitamente um conteúdo existente na estrutura cognitiva, na intenção de "substituir" o conteúdo que seria especificamente relevante à aprendizagem do novo conteúdo. O comparativo é usado para integrar e discriminar as novas informações (conceitos, proposições), sejam elas similares ou distintas, que se podem confundir com as existentes na estrutura cognitiva do aprendiz.

Moreira (2006), por sua vez, destaca que não se podem reduzir os OPs à função de simples comparações introdutórias. Deve-se usá-los, todavia, para identificar o conteúdo relevante dentro da estrutura cognitiva, explicar a relevância do conteúdo para a aprendizagem do novo material, propiciar uma visão mais ampla do material em um nível mais alto de abstração e, por fim, promover elementos organizacionais inclusivos, considerando efetivamente o que os aprendizes já sabem e destacando propriamente o conteúdo específico do novo material.

Moreira (2011), adverte que os OPs são estratégias instrucionais, usadas como propostas para manipular a estrutura cognitiva quando esta não possuir subsunçores adequados. A sua utilização não significa, porém, que o problema está resolvido, uma vez que ela não garante a ocorrência de aprendizagens significativas. Isso leva à necessidade de conhecerem-se os dois processos relacionados à ancoragem de conceitos durante a aquisição dessa forma de aprendizagem, a diferenciação progressiva e a reconciliação integradora.

De acordo com Ausubel (2002), na medida em que se aprende significativamente, fazse distinção dos significados adquiridos no processo de diferenciação progressiva, e isso ocorre progressivamente a fim de reconhecerem-se os detalhes e as especificidades entre conceitos. Simultaneamente à diferenciação progressiva, ele adverte que é preciso também 
DOI: https://doi.org/ 10.20396/zet.v26il.8650471

proceder à reconciliação integradora para resolver inconsistências e integrar significados, destacando que o excesso na diferenciação leva a perceber tudo diferente; caso o excesso seja na reconciliação, passa-se a perceber tudo igual. Logo, como adverte Moreira (2006), toda a aprendizagem resultante de uma reconciliação integradora implicará igualmente uma diferenciação progressiva adicional de conceitos e proposições.

Uma visão sobre a educação indígena brasileira através de alguns estudos recentes

A educação indígena brasileira é relativamente recente, se desconsiderarem as investidas realizadas no período da colonização portuguesa. De fato, as intenções pedagógicas não eram como as atuais. Conforme o trabalho de Schaden (1945 citado em Silva, 2014) que aparece como ponto de partida de uma nova forma educacional, mas já existem muitos esforços na mesma direção.

No período colonial português no Brasil, a prática pedagógica da Companhia de Jesus era fundamentada nas Constituições e na Ratio studiorum. Segundo Ferreira Jr. \& Bittar,

[...] as Constituições [...] declaravam que "são de muito proveito os estudos humanísticos de várias línguas", além da lógica, filosofia natural e moral, metafísica, teologia escolástica e Sagrada Escritura, como matérias que deviam ser estudadas. Quanto ao Ratio studiorum, para admitir novos candidatos, exigia a proposição de "algumas frases para se verterem em latim, ou, se for mister, para traduzirem de algum autor clássico" (2012, p. 701).

À época, a educação indígena voltava-se muito mais para a conversão dos nativos, e a dificuldade predominante entre as crianças indígenas e os padres jesuítas era linguística, já que estes não dominavam as línguas daquelas. A respeito da missão do visitador jesuíta na província, Faria (2014) argumenta que emerge a necessidade de negociar com Roma diante da realidade vivenciada in loco: a inaplicabilidade da pedagogia da vigilância e de alguns aspectos normativos, como o desejo de colocar tudo em ordem. Surge, assim, o conceito de negociação.

Silva \& Caldeira (2016) relatam que, durante séculos, a relação da sociedade com os indígenas era repressiva e física e culturalmente violenta, cuja finalidade era negar a própria identidade desses povos. Ainda de acordo com os autores, o Instituto Brasileiro de Geografia e Estatística (IBGE), no censo de 2010, informa que havia no país cerca de 896,9 mil indígenas, organizados em 305 etnias declaradas, com 274 línguas; dessa totalidade, mais de 342,8 mil estão na região norte e mais 78,8 mil, na região sul.

Nesse cenário de perdas e desigualdades acumuladas pelos povos indígenas no Brasil, desde o início da colonização, a educação, como propõem Bernardi \& Caldeira (2012), precisa encontrar um equilíbrio entre a tradição e a contemporaneidade. Eles propõem que a escola indígena deva ser esse lugar, pois

[...] é o espaço de reafirmação das identidades e da construção permanente de autonomia e alteridades, num desafio cotidiano, que busca permitir ao Kaingang de hoje o orgulho de ser nativo e lutar para reconstruir o projeto sociocultural de seu povo, onde possa se reconhecer como indígena Kaingang, fortalecer o sentimento de 
ser indígena, de sentir-se indígena, ao mesmo tempo em que estabelece diferentes relações com as sociedades de entorno (2012, p. 413).

Tem sido comum entre os que lidam com educação reconhecer a força do contexto no ato educativo; pode-se ilustrar isso a partir de vários estudos, mas a seguinte citação de Costa, Tenório \& Tenório (2014) é suficiente para justificar esse reconhecimento:

O momento histórico e o ambiente sociocultural em que o aluno está inserido devem ser considerados. Seja no ensino de Matemática para povos indígenas ou não, como também no ensino de outras ciências, é importante que a contextualização se faça sempre presente. Segundo D'Ambrosio (1997, p. 128): "contextualizar a matemática é essencial, seja para índios ou não" (2014, p. 1104).

Além desse atributo ao contexto, a escolha do objeto social e dos princípios teóricos a serem adotados para guiar a organização do material de ensino pode ser pedagogicamente decisiva. Teoricamente orientados pela educação matemática crítica (EMC), Bernardi \& Caldeira (2012), por exemplo, recorrem à forma de reação para lidar com as contradições e as desigualdades sociais vivenciadas pelos Kaingang, a partir de três conceitos estruturadores, o poder formatador da Matemática, a competência democrática e a ideologia da certeza.

No entanto, o interesse neste estudo volta-se para a intenção de viabilizar soluções favoráveis ao desempenho de competências democráticas para o povo pankará, como sugerido por Bernardi \& Caldeira (2012, p. 428-429), quando dizem que

[...] a EMC nos propõe pensar a educação matemática indígena com o propósito de potencializar o estudante à luz do cenário de sua cultura - seu contexto particular, uma educação matemática para o empowerment. Destacamos esse potencial com a noção de matemacia, que se refere ao indígena desenvolver a habilidade de lidar com noções matemáticas, de aplicar tais noções dentro e fora da terra indígena e de refletir sobre o resultado de tais aplicações, questionando os critérios utilizados na construção de tais noções e o significado do resultado encontrado. Confiabilidade e responsabilidade representam esteios para esse potencial, numa dimensão de educação crítica.

No estudo com crianças xakriabá, Silva (2014) chama atenção para considerarem-se dois aspectos durante a aprendizagem no contexto indígena. O primeiro deve ocorrer por meio de dois cuidados que se devem priorizar durante a organização de atividades, isto é:

[...] a forma como ocorre a participação e o engajamento da criança nas atividades cotidianas, [...] saber identificar como as atividades são estruturadas de forma que estabeleçam relações de aprendizado entre pessoas mais experientes e novos "chegantes" ou aprendizes [...]. [O] exercício de descrever a infância das crianças com base em sua circulação pelo território trouxe-nos informações relevantes sobre sua educação, sobretudo no que diz respeito aos aspectos essenciais da identidade e constituição étnica do grupo (2014, p. 668, grifo nosso).

No caso da educação indígena, essas prioridades podem servir de apoio para subsidiar o importante propósito ausubeliano atribuído à tarefa docente: criar formas de descobrir o que o(a) aprendiz já sabe para embasar o ensinamento. Recomenda-se, portanto, que o(a) professor(a) elabore propostas didáticas que viabilizem a articulação entre os aspectos da cultura própria e os conhecimentos institucionalizados que pretende ensinar. 
DOI: https://doi.org/ 10.20396/zet.v26il.8650471

\section{Abordagem metodológica}

As discussões sobre os mais variados tipos de pesquisas que tentam atender os interesses investigativos dos pesquisadores convergem para duas formas de abordagens, a quantitativa e a qualitativa. Quanto à segunda forma, de acordo com Creswell (2010, p. 26),

[...] é um meio para explorar e para entender o significado que os indivíduos ou os grupos atribuem a um problema social ou humano. O processo de pesquisa envolve as questões e os procedimentos que emergem, os dados tipicamente coletados no ambiente do participante, a análise dos dados indutivamente construída a partir das particularidades para os temas gerais e as interpretações feitas pelo pesquisador acerca do significado dos dados.

Conforme Gerhardt \& Silveira (2009, p. 35), esse enfoque é fundamental, pois "[o]bjetiva gerar conhecimentos para aplicação prática, dirigidos à solução de problemas específicos. Envolve verdades e interesses locais”. De modo mais específico, André (2008) lembra que os estudos de caso são extremamente úteis para conhecer os problemas e ajudar a entender a dinâmica da prática educativa, porque retratam um problema educacional em toda a sua complexidade individual e social e, por isso, são uma descoberta preciosa.

Elliott (2005) alega que a investigação-ação tem por objetivo melhorar a prática, em vez de gerar conhecimentos; assim, a produção e o emprego do conhecimento submetem-se a esse objetivo básico e a ele condiciona-se. Não obstante, Dionne (2007) aponta quatro fases no percurso da ação planejada na pesquisa-ação: a identificação das situações, a projetação da pesquisa e da ação, a realização das atividades previstas e a avaliação dos resultados obtidos.

Conforme a ordem da apresentação dessas fases da pesquisa-ação, neste estudo a primeira correspondeu à identificação de um enfoque da cultura pankará que permitisse uma articulação intercultural com algo do saber matemático institucionalizado. A segunda, trata dos planejamentos estratégicos voltados para o desenvolvimento da pesquisa. Já a terceira, dedica-se às intencionalidades educativas concernentes às perspectivas e expectativas almejadas com a realização desse intercâmbio cultura. Por fim, a última etapa avalia o alcance das intencionalidades educativas, considerando os pressupostos teóricos adotados.

\section{O contexto do estudo}

As cinco maiores populações brasileiras autodeclaradas indígenas, segundo os dados de 2010 do IBGE, são, em ordem decrescente por Unidade da Federação: Amazonas, Mato Grosso do Sul, Bahia, Pernambuco e Roraima, respectivamente com 168.680, 73.295, 56.381, 53.284 e 49.637. Desse universo, os Pankará, segundo dados do IBGE 2010, representam 2.074; dos quais 999 são do sexo masculino e 1075, do sexo feminino.

Florêncio (2016) afirma que no agreste e no sertão Pernambucano existem, conforme dados do IBGE 2010, aproximadamente uma população de 53.280 indígenas. Ele nomina cada uma das etnias, informando também os municípios onde estão localizadas:

Fulni-ô (Águas Belas), Xukuru do Ororubá (Pesqueira), Kapinawá (Ibimirim, Tupanatinga, Buíque), Kambiawá (Ibimirim), Pipipã (Floresta), Pankará (Carnaubeira 
DOI: https://doi.org/ 10.20396/zet.v26il.8650471

da Penha), Atikum (Carnaubeira da Penha e Floresta), Tuxá (Inajá), Pankararu (Tacaratu, Petrolândia e Jatobá), Pankauiká (Jatobá), Truká Assunção (Cabrobó) e Truká Tapera (Orocó) (2016, p. 28).

Depois de décadas marcadas por conflitos violentos em busca de direitos e autonomia, esses povos têm conseguido algumas conquistas. Entre elas está a territorial, que os dignifica com a possibilidade de permanência e uso dos bens existentes nos seus hábitats. Mas há perdas irreparáveis, como, em Pernambuco, a constatação de que apenas os Fulni-ô preservam a sua língua.

Cada direito adquirido é exaltado como uma conquista pelos povos indígenas. Graças à sua união e à sua organização na busca comum por dignidade, conseguiram a promulgação de alguns documentos que garantem legalmente esses direitos. Com a Convenção 169 da Organização Internacional do Trabalho (OIT) sobre Povos Indígenas e Tribais, promulgada no Brasil por meio do Decreto $\mathrm{n}^{\circ}$ 5.051/2004, surge o direito de uma educação escolar diferenciada, respaldada na Declaração Universal dos Direitos Humanos, de 1948, da Organização das Nações Unidas (ONU). Essa educação escolar diferenciada passou a integrar a Lei de Diretrizes e Bases da Educação Nacional, Lei n 9.394/1996, a partir da Resolução no 3/1999 e a no 5/2012, segundo os Pareceres no 14/1999 e no 13/2012 do Conselho Nacional de Educação/Câmara de Educação Básica (CNE/CEB). Além dessas resoluções, há outros documentos nacionais e internacionais que visam assegurar tanto o direito à educação como também o direito humano e social.

Esta pesquisa realizou-se graças ao consentimento da cacique ${ }^{6}$, dos pajés e das demais lideranças pankará (tanto das pessoas que detêm o conhecimento da ciência oculta junto com os pajés quanto dos representantes legais do povo para as tomadas de decisão sobre a garantia e permanência de direitos). Assim, foi possível fotografar momentos da atividade religiosa do toré, realizada por um grupo de quarenta indígenas pankará, no município de Carnaubeira da Penha, no estado de Pernambuco.

Para que se pudesse realizar este estudo, os Pankará reivindicaram, porém, algumas precauções que precisariam considerar-se e respeitar-se devidamente: combinar com antecedência as localidades a serem visitadas, os dias de visitas, quais seriam as pessoas que participariam da visita, a permissão para o uso de aparelhos eletrônicos, as formas de saudações etc. Tudo deveria cumprir as determinações preestabelecidas pelas lideranças.

Procedimentos para o desenvolvimento da pesquisa

Desenvolveu-se a pesquisa em três etapas. A primeira iniciou-se com uma análise sobre a educação indígena brasileira a partir de três periódicos nacionais da área de educação - um mais geral e dois mais específicos da educação matemática -, no período de 2012 a 2016. Classificaram-se os artigos dos periódicos, conforme o seu nível de relação com a temática, em pouco relacionados, relacionados indiretamente e relacionados diretamente.

\footnotetext{
${ }^{6}$ Entre os Pankará, este poder de liderança política é exercido por uma mulher.
} 
DOI: https://doi.org/ 10.20396/zet.v26il.8650471

$\mathrm{Na}$ Revista Brasileira de Educação (RBE), encontraram-se seis artigos, os pares $17(50)$ e 17(51), 17(51) e 19(57) e 19(58) e 21(67), respectivamente, pouco relacionados, relacionados indiretamente e relacionados diretamente. No Boletim de Educação Matemática (Bolema), no número 30(56), há um artigo pouco relacionado; e, nos números 26(42B), 28(50), 29(53) e 30(56), há um artigo em cada relacionado diretamente. Por fim, para destacar a importância da iniciativa da revista Zetetiké, cabe o registro de que nesse período do levantamento não há artigo algum que aborde a temática da educação indígena brasileira.

A segunda etapa consistiu em desvelar um aspecto da cultura pankará que ampliasse, de forma didático-epistemológica, o desempenho das tarefas escolares indígenas do(a) educador(a) e das crianças para promover uma aprendizagem significativa de matemática. $\mathrm{O}$ intercâmbio cultural está atento aos cuidados com a identificação de atividades estruturadas e com os fundamentos essenciais da identidade e da constituição étnica dos povos indígenas, apontados por Silva (2014) no seu estudo com crianças xacriabás. Silva também recorre à competência democrática como aspecto da educação matemática crítica, proposta por Bernardi \& Caldeira (2012), para ajudar os Kaingang a lidarem com as contradições e desigualdades sociais.

A terceira e última etapa cuidou da planificação de uma proposta educativa para possibilitar o compartilhamento entre atividades pankará e objetos da cultura matemática, em relação aos sistemas de valores, normas, símbolos, crenças e conhecimentos a serviço de um intercâmbio cultural. A busca dos indígenas por mudanças para a manutenção da sua identidade cultural orientou a escolha do toré - como atividade cultural - e a do círculo como objeto matemático. Os organizadores prévios, por sua vez, além dos intentos ausubelianos, permitem trazer para o debate a interculturalidade, na medida em que serão pensados e formulados a partir do reconhecimento de aspectos importantes a serem trocados entre esses espaços culturais, buscando não danificar a identidade dos Pankará.

\section{O ritual do toré como organizador prévio para o conceito de círculo}

Este estudo almeja uma abordagem didático-epistemológica contextualizada para viabilizar o ensino de círculo e seus elementos na cultura pankará a partir do ritual sagrado do toré. Para isso, investiu-se na exploração de aspectos da cultura local, a fim de levar as crianças a construírem habilidades para lidar com o conhecimento matemático em situações dentro e fora do seu convívio natural, como sugerido por Bernardi \& Caldeira (2012).

Um dos autores deste estudo é nativo do povo pankará e trabalha há mais de dez anos como educador. Certamente, adquiriu vasta experiência por atuar em diversos níveis de ensino. Ao longo do percurso docente, a sua experiência vivida durante um ano, quando ministrou aulas de arte indígena, conferiu-lhe uma maior preparação para atuar nas relações interculturais que contribuem para a preservação e o desenvolvimento das gerações futuras. Nessas condições, está mais habilitado para opinar sobre a organização de atividades que contemplem os dois cuidados apontados anteriormente por Silva (2014). 
$\mathrm{O}(\mathrm{a})$ educador(a) de arte indígena dispõe de uma grande variedade de atividades que apoiaria os propósitos didático-pedagógicos a serem vivenciados no ensino de matemática. Basta imaginar a diversidade de bens materiais e imateriais existentes em qualquer cultura, seja ela indígena ou não. De um lado, tem-se a confecção de adornos corporais, como enfeites e outros objetos; por outro, a prática de rituais, como o toré.

O ritual do toré tem costumeiramente por ação inicial a realização de uma oração em que o pajé solicita ao pai eterno, Tupã, permissão e proteção para começar a desenvolver as ações que constituem a atividade do próprio ritual sagrado e, conforme o seu Projeto Políticopedagógico (2012), representa a base da organização social do povo pankará. A segunda ação consiste em cantar hinos (toantes) como sendo uma introdução. Até esse momento do ritual, não se configura ainda a formação de uma imagem que indique uma figura geométrica.

Concluída essa parte, o pajé e o contramestre - no caso, a sua esposa - iniciam o referido trabalho, que conta com a presença, em alguns momentos, da cacique, de outras lideranças e dos caboclos ${ }^{7}$. No posicionamento dos participantes, no momento da formação do círculo/circularidade, os quatro primeiros componentes da frente a conduzirem a formação são sempre homens. Em um dado momento, emerge uma figura geométrica, o círculo; porque o movimento dos participantes, na prática do ritual, leva-os à formação de uma "roda", na linguagem dos caboclos.

Após a escolha do terreiro ${ }^{8}$, demarca-se o cruzeiro ${ }^{9}$. Para aludir ao cerimonial, há inicialmente a fixação do cruzeiro, conduzido pelo pajé com a participação da cacique, de outra liderança e do educador pankará (figura 1). Na sequência, acontecem mais dois momentos do ritual que ilustram o início da formação do círculo (figura 2) e a sua obtenção (figura 3) com a participação dos caboclos.

\footnotetext{
7 Mendonça (2003, p. 62), reporta-se à presença de três terminologias nos discursos indígenas sobre a identidade: 'Para eles o caboco (como pronunciam) é o ‘nós' (indígena) em relação ao ‘outro' que é o não-índio (branco) e o negro (cativo)."

${ }^{8}$ Local identificado com um cruzeiro, que tem na sua base artefatos sagrados, como imagens de santos, peças obtidas de sítios arqueológicos e a jurema. Fica próximo das casas, como no Enjeitado e na Lagoa, ou mais próximo das matas, como na Cacaria que juntas correspondem as três aldeias mais tradicionais dos Pankará.
}

${ }^{9}$ Estrutura de madeira na forma de uma cruz que representa o símbolo cristão da religiosidade do povo. 
DOI: https://doi.org/ 10.20396/zet.v26il.8650471

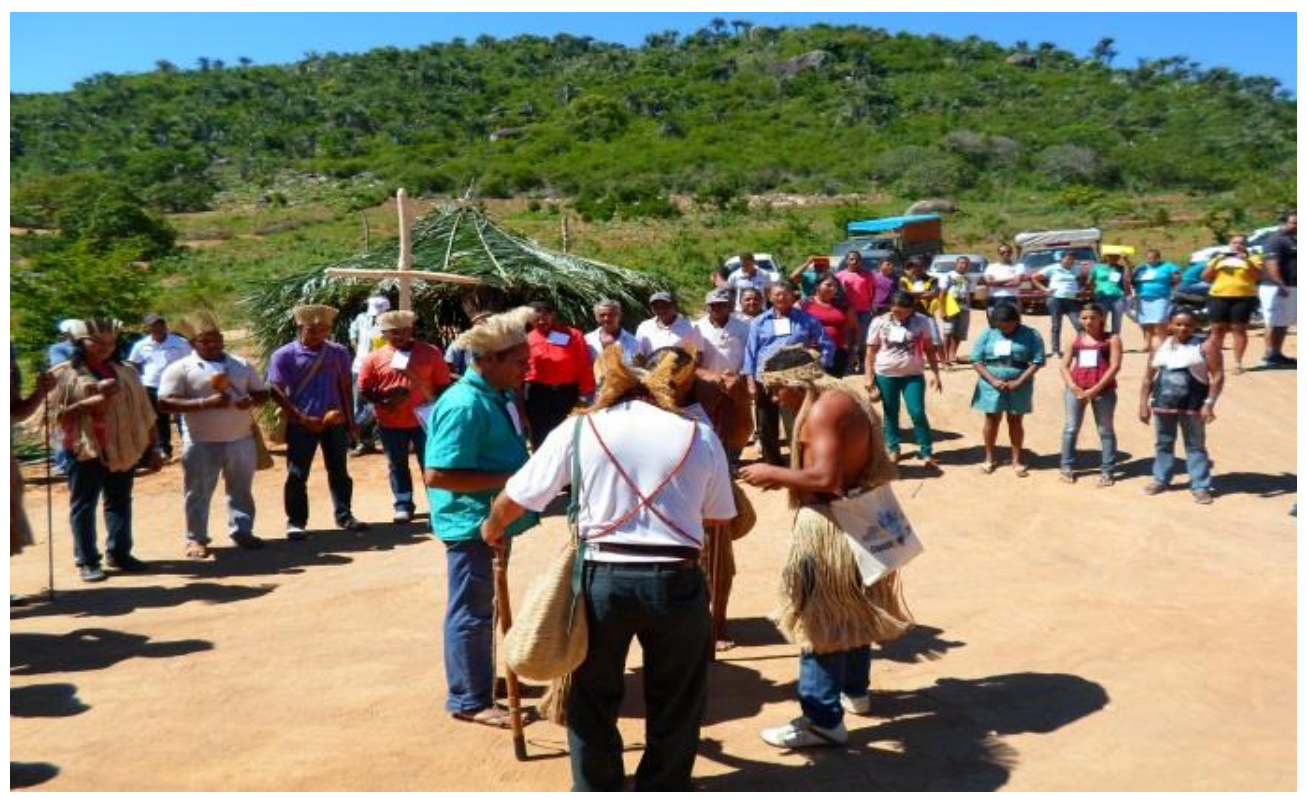

Figura 1 - $\mathrm{O}$ marco fincado no terreiro Fonte: Arquivo pessoal dos autores

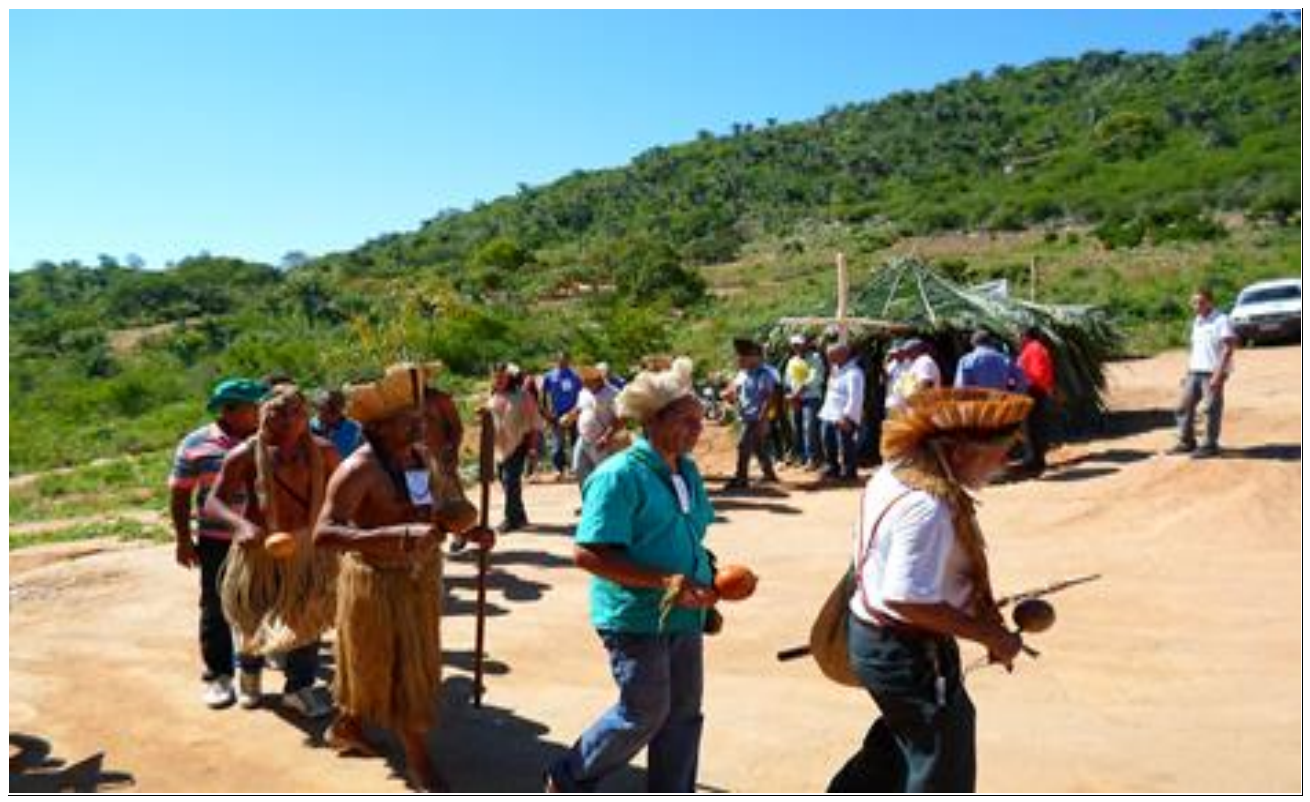

Figura 2 - Início da formação do círculo

Fonte: Arquivo pessoal dos autores 
DOI: https://doi.org/ 10.20396/zet.v26il.8650471

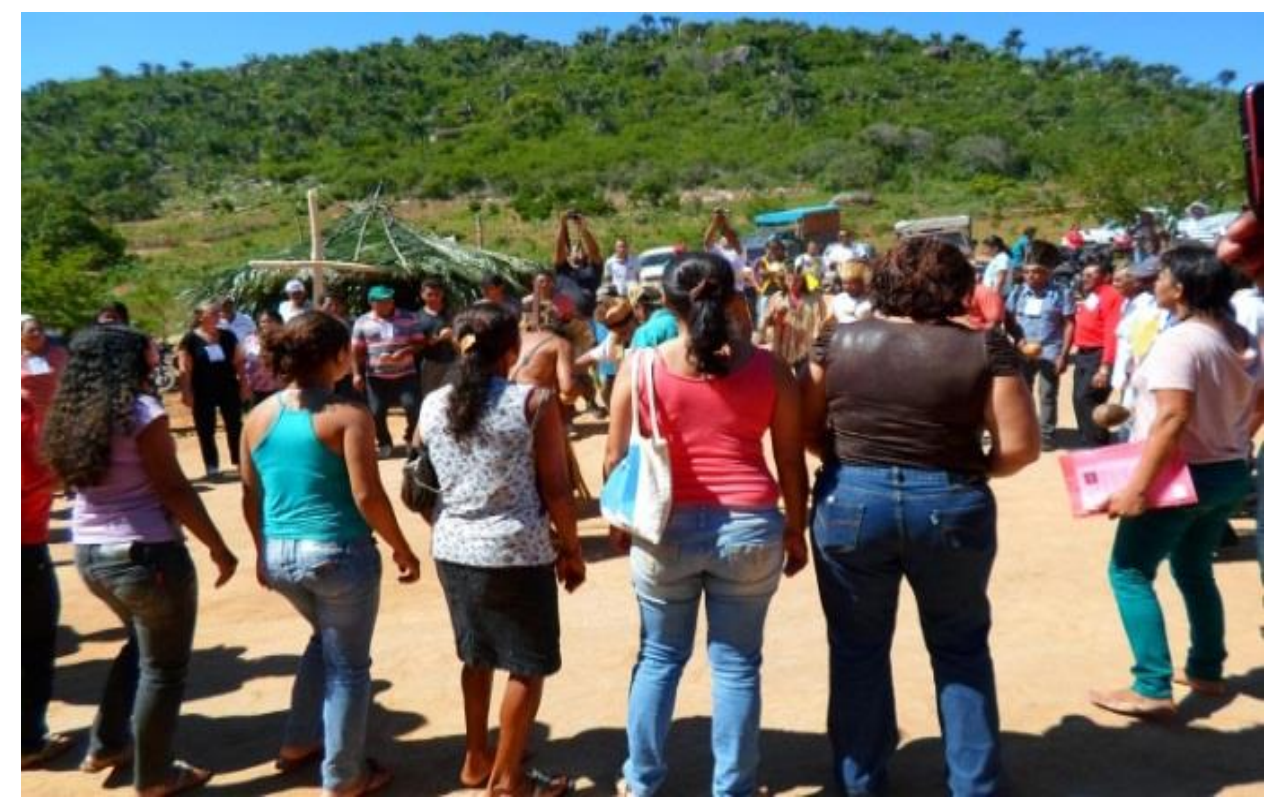

Figura 3 - Círculo estabelecido

Fonte: Arquivo pessoal dos autores

A forma circular representada na figura 3 pode encontrar-se, inclusive, em adornos corporais, como em colares, pulseiras, maracá10 e na cataioba11. Esses materiais são utilizados em muitas atividades da cultura pankará e também existem em outras culturas indígenas no Brasil.

\section{Os conceitos inerentes à idealização de círculo e os seus elementos na atividade do toré}

O aporte didático-pedagógico advém de caminhos desvelados por meio de pressupostos da Teoria da Aprendizagem Significativa (Ausubel, 2002), em particular, no que se refere aos organizadores prévios, que servem de ponte cognitiva inicial entre aspectos da cultura indígena e da cultura matemática institucionalizada. A figura 4 representa um mapa conceitual que sintetiza as intenções educativas nesse contexto.

\footnotetext{
${ }^{10}$ Instrumento feito da planta cabaça utilizado para demarcar o compasso e o ritmo da dança no ritual do toré.

11 Trata-se de uma forma de saia feita da fibra do caroá.
} 


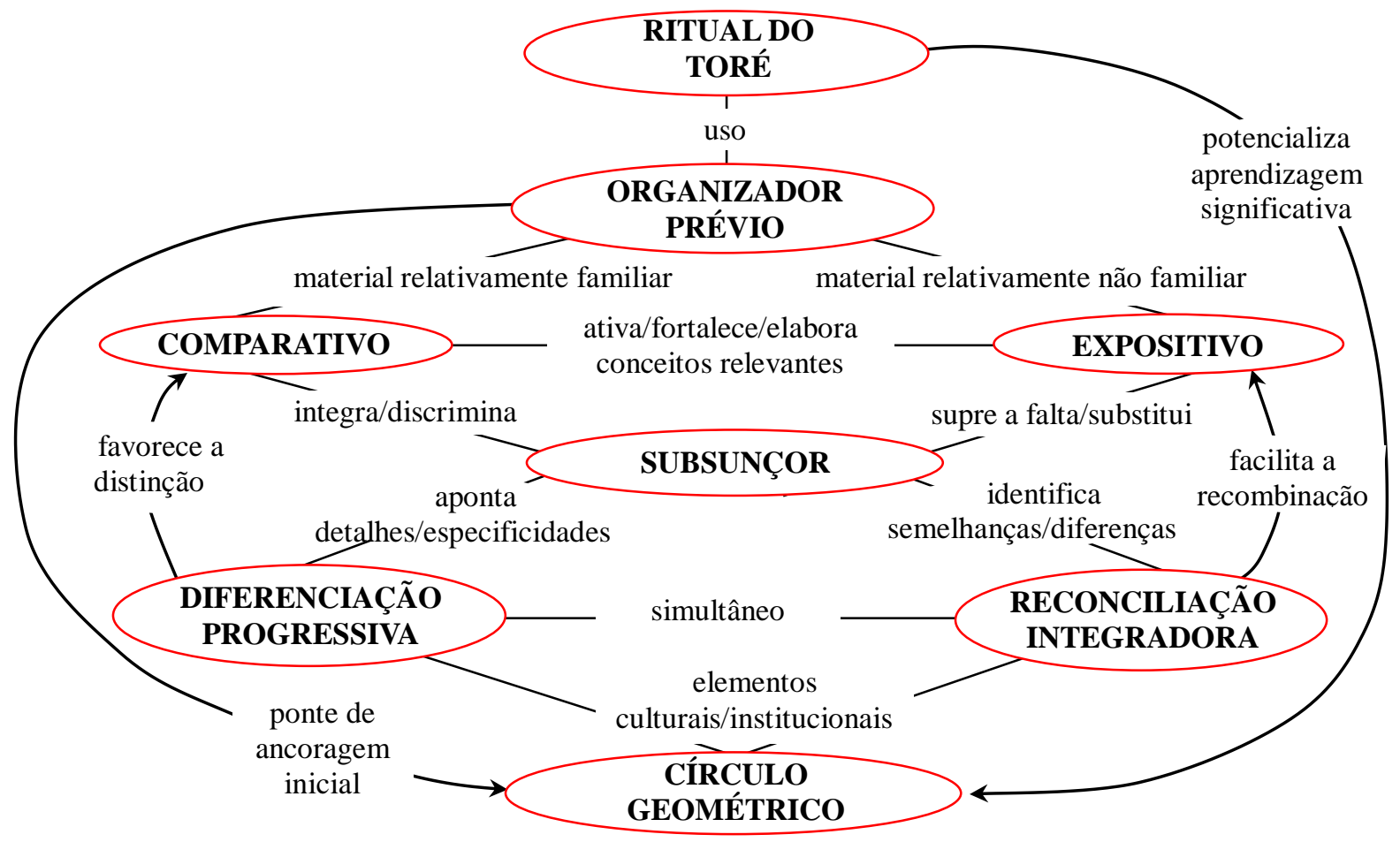

Figura 4 - Ritual do toré como organizador prévio para o conceito de círculo

Fonte: Arquivo pessoal dos autores

O ensino de círculo e os seus elementos na escola indígena pode ser abordado por meio de aproximações contextualizadas pelo educador indígena, como as caracterizadas neste trabalho a partir das citações de Serres (1991), desde que os contextos planificados atuem como organizadores prévios comparativos por se tratar de algo familiar as crianças pankará. Assim, visando obter ajustes adequados para essa planificação inicial, o educador indígena precisa levantar as concepções prévias das crianças envolvidas no processo educativo, solicitando-as que, por exemplo, produzam desenhos para representar o ritual do toré.

Após esses ajustes, as atividades a serem vivenciadas precisam, além de exitosas em termos da passagem do nível informal para o mais formal sobre círculo, circunferência, raio, corda e diâmetro, fortalecer os valores e as crenças das crianças pankará sobre as formas de lidar com as relações de contradições e desigualdades sociais. Diante dessa caracterização, percebe-se que não se trata apenas de explorar condições como admitir as cabeças dos indígenas como pontos, se observadas do alto, mas de apostar na possibilidade de reconhecimento de uma "roda", quando todos os participantes do toré estiverem posicionados a uma mesma distância do cruzeiro.

Os intentos educativos de relacionar aspectos da cultura indígena com outras culturas, em particular, com a cultura matemática - envolvendo trocas e/ou fusões -, estão mais voltados para os processos de aculturação. Porém, a viabilidade educativa para explorarem-se devidamente as definições que seguem depende do educador pankará, por ser alguém que 
DOI: https://doi.org/ 10.20396/zet.v26il.8650471

transita em ambas as culturas, domina o contexto cultural próprio, entende as necessidades sociais, políticas e de preservação e por conhecer os limites e os benefícios da cultura matemática para o seu povo.

Círculo. Após a formação da "roda" pelo pajé, se for mantida a condição de que a cabeça de cada caboclo do cerimonial religioso, observada de cima para baixo, estiver à mesma distância da vara fincada no meio da "roda", toda a região interior, ou seja, a parte que contém o cruzeiro, chamar-se-á círculo.

Circunferência. Após a formação do círculo, se forem mantidas as condições de que, se vista de cima para baixo, a cabeça de cada caboclo representa um ponto, e, se for preservada a mesma distância entre cada cabeça em relação ao cruzeiro, a linha de contorno do círculo chamar-se-á circunferência.

Raio. Após a formação da "roda" - em particular, o seu contorno (circunferência) -, representa-se o raio pela medida do segmento que vai da cabeça de cada indígena à estaca fincada no meio do meio do terreiro (cruzeiro).

Corda. Compreende-se por corda a medida do segmento que vai da cabeça de um indígena qualquer em relação à cabeça de outro, desde que não passe pelo cruzeiro (centro), no entorno do qual se formou a circunferência.

Diâmetro: Denomina-se diâmetro a medida do segmento tomado da cabeça de um indígena qualquer em relação à cabeça de outro, desde que passe exatamente pelo cruzeiro, dividindo o círculo em duas partes iguais, chamadas de semicírculos.

\section{Considerações educacionais}

As contribuições da educação matemática para o ensino da matemática têm sido corroboradas em muitos estudos. Esse campo investigativo - no que tange à exploração do caráter filosófico e social da matemática a partir da vivência das práticas culturais, costumes, crenças e tradições - vem mostrando-se frutífero no processo de ensino e aprendizagem; mas, no caso dos povos originários, o(a) educador(a) precisa conhecer devidamente o contexto para não recorrer a situações educativas constrangedoras.

A exploração de ideias matemáticas no contexto cultural dos povos indígenas, em situações que envolvem valores emocionais e sociais no nível informal (Davies, 1973), parece viável. No caso dos Pankará, é um acesso a competências democráticas, a formas de empoderamento, para lidar com as contradições e as desigualdades, como destacam Bernardi \& Caldeira (2012).

As explicações para essas preocupações são diversas. Mesmo com direitos e deveres garantidos por leis, os povos indígenas ainda sofrem para assegurarem a prática das suas atividades socioculturais como ação educativa nas escolas. Por outro lado, a aproximação dos povos não indígenas tem fortalecido as causas dos movimentos indígenas e contribuído 
positivamente para a resistência contra a desigualdade social e para despertar o conhecimento das ciências e da tecnologia.

Esta proposta planificada para o ensino de círculo e dos seus elementos procura não subestimar nem negligenciar o conhecimento dos povos indígenas; ao contrário, almeja desvelar caminhos para oportunizar a aquisição de conhecimento formal aos Pankará, propiciando-lhes condições para valerem-se dessa forma de saber diante de certas situações que lhes forem impostas.

A retribuição à colaboração valiosa prestada direta e indiretamente pelos Pankará para a realização deste estudo acontece em três instâncias. A primeira consistiu na formação de um especialista pankará em ensino de matemática. A segunda foi a reapresentação da defesa da monografia desse especialista na aldeia, com exposição de fotografias e de parte da filmagem produzida ao longo da defesa na faculdade. A última instância prevê uma intervenção desse especialista em aulas para crianças pankará utilizando a proposta produzida.

O projeto de intervenção parte do pressuposto de que o educador pankará, por estar imerso nas duas culturas, poderá ajustar as atividades de ensino da proposta didática deste estudo a partir das concepções prévias das crianças pankará, considerando as suas práticas e tradições, em conformidade com os limites e os benefícios da cultura matemática para o seu povo. O propósito do uso de organizadores prévios ausubelianos decorre do credenciamento atribuído ao papel do contexto neste estudo, por entender que isso aumenta a possibilidade de coesão entre o que o aprendiz já sabe sobre a sua própria cultura com o saber matemático que se deseja ensinar.

\section{Referências}

Ausubel, D. P. (2002). Adquisición y retención del conocimiento una perspectiva cognitiva. Barcelona: Paidós.

Ausubel, D. P., Novak, J. D. \& Hanesian, H. (1978). Educational psychology: a cognitive view. 2. ed. Nova York: Holt, Rinehart and Winston.

Barbalho, J. I. S. (2012). Discurso como prática de transformação social: o político e o pedagógico na educação intercultural Pankaká. Tese de Doutorado. Recife: Universidade Federal de Pernambuco. Retirado em 17 de janeiro, 2016, de: <http://repositorio.ufpe.br:8080/bitstream/handle/123456789/13006/Jos\%C3\%A9Ivamils on_Tese.pdf?sequence $=1$ \&isAllowed=y $>$.

Bernardi, L. S. \& Caldeira, A. D. (2012). Educação Matemática na Escola Indígena sob uma Abordagem Crítica. Bolema, 26(42B), 409-431.

Bishop, A. J. (1999). Enculturación Matemática: La educación matemática desde una perspectiva cultural. Barcelona: Paidós.

Brasil (2004). Decreto n. 5.051, de 19 de abril de 2004. Promulga a Convenção n. 169 da Organização Internacional do Trabalho - OIT sobre povos indígenas e tribais. Brasília. Retirado em 15 de junho, 2017, de: www.planalto.gov.br. 
DOI: https://doi.org/ 10.20396/zet.v26il.8650471

Brasil (1996). Lei n ${ }^{\circ}$ 9.394, de 20 de dezembro de 1996. Estabelece as Diretrizes e Bases da Educação Nacional. Diário Oficial da União, seção 1. Brasília: Presidência da República.

Costa, B. J. F., Tenório, T. \& Tenório A. (2014). A Educação Matemática no Contexto da Etnomatemática Indígena Xavante: um jogo de probabilidade condicional. Bolema, 28(50), 1095-1116.

Creswell, J. W. (2010). Projeto de pesquisa: métodos qualitativo, quantitativo e misto. 3. ed. Porto Alegre: Artmed.

D’Ambrosio, U. (1997). A era da consciência: aula inaugural do primeiro curso de pósgraduação em ciências e valores humanos no Brasil. São Paulo: Editora Fundação Peirópolis.

Dionne, H. (2007). A pesquisa-ação para o desenvolvimento local. Brasília: Liber Livro Editorial.

Elliott, J. (2005). La investigación-acción en educación. 4. ed. Madrid: Ediciones Morata.

Faria, M. R. (2014). A organização de um corpo disperso: uma análise da atividade jesuítica em terras brasílicas (1583). Revista Brasileira de Educação, 19(57), 417-440.

Ferreira Jr., A. \& Bittar, M. (2012). Artes liberais e ofícios mecânicos nos colégios jesuíticos do Brasil colonial. Revista Brasileira de Educação, 17(51), 693-751.

Florêncio, R. R. (2016). Educação e letramento intercultural na aldeia de Assunção do povo Truká. Dissertação de Mestrado. Juazeiro: Universidade do Estado da Bahia. Retirado em 12 de maio, 2017, de: http://ppgesa.uneb.br/wp-content/uploads/2016/08/RobertoRem\%C3\%ADgio-Flor\%C3\%AAncio.pdf.

Gerdes, P. (2010). Da etnomatemática a arte-design e matrizes cíclicas. Belo Horizonte: Autentica Editora.

Gerhardt, T. E. \& Silveira, D. T. (Orgs.). (2009). Métodos de Pesquisa. Porto Alegre: Editora da UFRGS.

Instituto Brasileiro de Geografia e Estatística - IBGE. (2010). Censo Demográfico - 2010. Rio de Janeiro: IBGE. Recuperado em 15 de junho de 2017, de: www.ibge.gov.br.

Mendonça, C. F. L. (2003). "Os índios da Serra do Arapauá": identidade, território e conflito no sertão de Pernambuco. Dissertação de mestrado. Recife: Universidade Federal de Pernambuco. Retirado em 25 agosto, 2017, de: https://repositorio.ufpe.br/bitstream/handle/123456789/17471/dissertacao_CarolineFarias Leal_PPGAntrop_2003.pdf?sequence=1\&isAllowed=y

Moreira, M. A. (2006). A teoria da aprendizagem significativa e sua implementação em sala de aula. Brasília: Editora Universidade de Brasília.

Moreira, M. A. (2011). Aprendizagem significativa: a teoria e textos complementares. São Paulo: Editora Livraria da Física.

Novak, J. (1981). Uma teoria de educação. São Paulo: Pioneira.

Pernambuco. SEDUC - Secretária de Educação do Estado de Pernambuco. (2012). Projeto Político Pedagógico do povo Pankará - Memória do passado, saberes do presente: história, luta, ciência e resistência. Recife: Secretaria Estadual de Educação.

Zetetiké, Campinas, SP, v.26, n.1, jan./abr. 2018, p.75-93

ISSN 2176-1744 
DOI: https://doi.org/ 10.20396/zet.v26il.8650471

Ribeiro, D. (2002). Os índios e a civilização: a integração das populações indígenas no Brasil Moderno. 7. ed. São Paulo: Companhia das Letras.

Rosa, M. \& Orey, D. C. (2012). O campo de pesquisa em etnomodelagem: as abordagens êmica, ética e dialética. Educ. Pesqui., São Paulo, 38(04), 865-879.

Serres, M. (1991). Historia de las Ciencias. Madrid: Catedra.

Silva, R. C. (2014). Participação e aprendizagem na educação da criança indígena. Revista Brasileira de Educação, 19(58), 655-670.

Silva, S. F. \& Caldeira, A. D. (2016). Etnomatemática do Sistema de Contagem Guarani das Aldeias Itaty, do Morro dos Cavalos, e M'Biguaçu. Bolema, 30(56), 992-1013.

Recebido em: 30/09/2017

Aprovado para publicação em: 02/02/2018 